\title{
Sex differences in uric acid levels in kidney transplant recipients and their donors: a preliminary retrospective cross-sectional study
}

Mineaki Kitamura ${ }^{1,2^{*}}$, Yasushi Mochizuki ${ }^{1,3}$, Tsuyoshi Matsuda $^{3}$, Yuta Mukae $^{3}$, Hiromi Nakanishi ${ }^{3}$, Yuki Ota ${ }^{2}$, Tadashi Uramatsu², Yoko Obata ${ }^{2}$, Hideki Sakai ${ }^{3}$, Hiroshi Mukae ${ }^{4}$ and Tomoya Nishino ${ }^{2}$

\begin{abstract}
Background: Higher serum uric acid (UA) levels are associated with poorer renal prognosis. In kidney transplantation, both donors and recipients are diagnosed as having chronic kidney diseases (CKD) based on renal function; however, their UA levels slightly vary. Elucidating the differences in UA would help improve kidney prognosis, especially for recipients. Therefore, we investigated UA levels in kidney transplant recipients by comparing them to those in their donors.

Methods: In this retrospective cross-sectional survey, background information and blood examination results were collected from the donors just before donation and after transplantation in the donors and recipients. Associations between UA and sex estimated glomerular filtration rate (eGFR), and body mass index (BMI) were evaluated. Data were assessed by the Wilcoxon rank-sum test for continuous variables and the chi-squared test for categorical variables; multiple linear regression analyses were performed to determine which factors were associated with renal function before and after transplantation.

Results: Participant characteristics were as follows. The mean donor age ( $n=45,16$ men and 29 women) was $55 \pm$ 11 years, and the mean recipient age ( $n=45,25$ men and 20 women) was $46 \pm 16$ years. Sex-related differences (UA levels in men were predominant) existed in the UA of donors before $(P<0.001)$ and after donation $(P<0.001)$. Conversely, there were no significant sex-related differences in the UA of recipients $(P=0.51)$; the mean standardized eGFRs were similar in donors and recipients after transplantation. Multivariate linear regression analysis showed donor UA only correlated with donor sex before donation $(P=0.008)$. After donation, donor UA was associated with donor sex $(P=0.006)$, eGFR $(P<0.001)$, and BMI $(P=0.02)$. Notably, the UA of recipients after transplantation was only associated with eGFR $(P=0.003)$.

Conclusions: Sex has less impact on UA in recipients than in donors. UA has a greater impact on renal prognosis in women than men, even at the same UA level. Therefore, attention should be given to UA levels in female recipients. These findings can be useful for determining patient prognosis following kidney transplantation in both donors and recipients.
\end{abstract}

Keywords: Uric acid, Kidney transplantation, Sex, Glomerular filtration rate, Chronic kidney disease

* Correspondence: minekitamura@nagasaki-u.ac.jp

${ }^{1}$ Division of Blood Purification, Nagasaki University Hospital, 1-7-1 Sakamoto,

Nagasaki 852-8501, Japan

2Department of Nephrology, Nagasaki University Hospital, Nagasaki, Japan

Full list of author information is available at the end of the article

(c) The Author(s). 2019 Open Access This article is distributed under the terms of the Creative Commons Attribution 4.0 International License (http://creativecommons.org/licenses/by/4.0/), which permits unrestricted use, distribution, and reproduction in any medium, provided you give appropriate credit to the original author(s) and the source, provide a link to the Creative Commons license, and indicate if changes were made. The Creative Commons Public Domain Dedication waiver (http://creativecommons.org/publicdomain/zero/1.0/) applies to the data made available in this article, unless otherwise stated. 


\section{Background}

Serum uric acid (UA) levels are affected by renal function and lifestyle factors, such as diet and body size [1]. Sex-related differences are also associated with serum UA levels. It is well known that the UA levels of women tend to be lower than those of men, especially in younger and healthier people. However, postmenopausal women have elevated serum UA levels, which can be explained by higher levels of estrogenic compounds in the serum [2]; estrogen promotes the excretion of UA from the kidney [3]. In patients with chronic kidney disease (CKD), elimination of UA is significantly affected by deteriorating renal function, and administration of drugs, such as diuretics $[4,5]$.

Higher serum UA levels may be associated with poorer renal prognosis and adequate intervention is often necessary, especially in CKD patients [4]. Multiple studies have shown that UA levels are associated with the onset and pathogenesis of renal diseases, such as benign nephrosclerosis $[1,6]$. Furthermore, higher UA levels induce hypertension and cardiovascular diseases [1]. Therefore, urate-lowering drugs, such as xanthine oxidase inhibitors ( $\mathrm{XO}$ inhibitors), may be prescribed to CKD patients to delay the progression of renal dysfunction in patients with hyperuricemia $[7,8]$.

In kidney transplantation, both donor and recipients will be categorized as CKD patients after transplantation due to their estimated glomerular filtration rate (eGFR) [9]; their serum UA levels should also be considered in order to improve renal prognosis. Previous reports have shown that higher UA levels are associated with poor prognosis following kidney transplantation [10-12]. Unlike general CKD patients who are diagnosed with diabetic nephropathy or nephrosclerosis, the UA of kidney transplant recipients might be modulated differently because more kidney transplant recipients tend to be on polypharmacy, including immunosuppressants and corticosteroids. To compare kidney transplant recipients with general CKD patients, patients who match for renal function and other factors will be needed. Regarding kidney transplant recipients and donors, the transplanted kidney and contralateral kidney of the donor are supposed to have similar function; donors do not have urinary abnormalities both before and after donation, but have slightly decreased eGFR, resembling symptoms of nephrosclerosis patients.

Although almost all kidney transplant recipients are diagnosed with CKD, there may be differences in UA modulation between general CKD patients and kidney transplant recipients. Few studies have investigated the differences in UA modulation between CKD patients and kidney transplant recipients.

To elucidate these differences, we compared kidney transplant donors, whose eGFR would be classified as
CKD stage 3 after donation, and kidney transplant recipients.

\section{Methods \\ Study design}

This was a cross-sectional, single-center study. We examined both donors and recipients older than 18 years of age who underwent living kidney transplantation at Nagasaki University Hospital from January 2008 to December 2017. Exclusion criteria for this study included age younger than 18 years and prescription of uratelowering drugs and/or diuretics to donors or recipients. Patients who were excluded due to the use of uratelowering drugs were only included for investigating the prevalence of hyperuricemia. Hyperuricemia of recipients was defined according to a previous report [12], as follows: UA levels $>7 \mathrm{mg} / \mathrm{dL}$ in males and $>6 \mathrm{mg} / \mathrm{dL}$ in females, or the use of $\mathrm{XO}$ inhibitors.

\section{Data collection}

Patient information including age, sex, causes of renal dysfunction, and history of diabetes or hypertension was collected along with donor background information and blood examination results. Blood collection was performed just before donation and the closest point 1 year after donation (donor) and only 1 year after transplantation (recipient). The data collection of recipients was performed 1 year after transplantation because of the hypothesized decline in native renal function of the recipient [13]. eGFR was calculated by using the formula of the Japanese Society of Nephrology: eGFR $=194 \times($ serum creatinine $)^{-1.094} \times(\mathrm{age})^{-0.287} \times(0.739$, if female $)$ [14].

\section{Statistical analyses}

Statistical analyses were performed using JMP 13 software (SAS Institute, Inc., NC, USA). Categorical variables were expressed as number (\%), whereas continuous values were expressed as mean \pm standard deviations (SD). If data were not normally distributed, median values with interquartile range were shown. The Wilcoxon rank-sum test was used for continuous variables, while the chi-squared test was used for categorical variables. Multiple linear regression analyses were performed in order to elucidate the factors which were associated with renal function before transplantation and 1 year after transplantation. $P<0.05$ was considered statistically significant. Considering the effect on serum UA level and data availability, the constitutional parameters were predetermined to be sex, eGFR, and body mass index (BMI).

\section{Results}

The sample size of the donors and recipients was $n=45$ for each group. The mean donor age was $55 \pm 11$ years 
and donors included 16 men and 29 women. The mean recipient age was $46 \pm 16$ years, and recipients included 25 men and 20 women. Seventeen recipients and one donor were excluded. One recipient (male) was prescribed an $\mathrm{XO}$ inhibitor and diuretics, 15 recipients were prescribed XO inhibitors (4 males, 11 females), and one recipient (male) left our hospital 1 year after transplantation. In the donor group, one donor was excluded due to the use of an XO inhibitor before and after donation, but his recipient was also prescribed an $\mathrm{XO}$ inhibitor 1 year after transplantation. The characteristics of the donors and the recipients before transplantation are shown in Table 1.

Figure 1 shows the correlations between donor UA level and sex, eGFR, and BMI before donation. The UA level of male donors $(5.9 \pm 1.1 \mathrm{mg} / \mathrm{dL})$ was significantly

Table 1 Characteristics of donors and recipients

\begin{tabular}{|c|c|c|}
\hline & Donors & Recipients \\
\hline Age (years) & $55 \pm 11$ & $46 \pm 16$ \\
\hline Sex ratio; male:female & $16: 29$ & $25: 20$ \\
\hline Height (cm) & $159 \pm 8$ & $163 \pm 9$ \\
\hline Body weight (kg) & $57 \pm 12$ & $56 \pm 12$ \\
\hline Body mass index $\left(\mathrm{kg} / \mathrm{m}^{2}\right)$ & $22.5 \pm 3.6$ & $21.0 \pm 3.8$ \\
\hline \multicolumn{3}{|l|}{ Complications } \\
\hline Hypertension & $7(16 \%)$ & $31(67 \%)$ \\
\hline Hyperlipidemia & $6(13 \%)$ & $23(51 \%)$ \\
\hline Diabetes & $0(0 \%)$ & $14(31 \%)$ \\
\hline Blood relatives & $27(60 \%)$ & \\
\hline Dialysis vintage (months) ${ }^{a}$ & & $23(2-82)$ \\
\hline Preemptive kidney transplantation & & $11(24 \%)$ \\
\hline \multicolumn{3}{|l|}{ Causes of renal failure } \\
\hline Chronic glomerulonephritis & & $24(53 \%)$ \\
\hline Diabetic nephropathy & & $4(9 \%)$ \\
\hline CAKUT & & $3(7 \%)$ \\
\hline ANCA associated vasculitis & & $3(7 \%)$ \\
\hline ADPKD & & $3(7 \%)$ \\
\hline Lupus nephritis & & $2(4 \%)$ \\
\hline Others and unknown & & $6(13 \%)$ \\
\hline \multicolumn{3}{|l|}{ Immunosuppressant } \\
\hline Mycophenolate mofetil & & $42(93 \%)$ \\
\hline Mizolibin & & $2(4 \%)$ \\
\hline Everolimus & & $22(49 \%)$ \\
\hline Tacrolimus & & $42(93 \%)$ \\
\hline Cyclosporin & & $3(7 \%)$ \\
\hline mPSL & & $45(100 \%)$ \\
\hline
\end{tabular}

CAKUT, congenital anomalies of the kidney and urinary tract; $A N C A$, antineutrophil cytoplasmic antibody; $A D P K D$, autosomal dominant polycystic kidney disease; MMF, mycophenolate mofetil; $M P S L$, methylprednisolone ${ }^{a}$ Median (interquartile range) higher than that of female donors $(4.3 \pm 1.0 \mathrm{mg} / \mathrm{dL} ; P<$ $0.001)$, and the UA level was correlated with BMI $\left(r^{2}=\right.$ $0.15, P=0.01)$, but not with eGFR $\left(r^{2}=0.02, P=0.33\right)$. The systolic and diastolic blood pressure of donors before donation was $124 \pm 16 \mathrm{mmHg}$ and $74 \pm 10 \mathrm{mmHg}$, respectively, and there were no significant correlations between blood pressures and UA levels (data not shown). After donation, the UA level of male donors $(6.3 \pm 1.3 \mathrm{mg} / \mathrm{dL})$ was also significantly higher than that of female donors $(4.6 \pm 1.0 \mathrm{mg} / \mathrm{dL} ; P<0.001)$, and the UA level was weakly correlated with eGFR $\left(r^{2}=0.11, P\right.$ $=0.03)$ and BMI $\left(r^{2}=0.11, P=0.02\right)$ (Fig. 2). The systolic and diastolic blood pressure of donors after donation was $120 \pm 14 \mathrm{mmHg}$ and $74 \pm 11 \mathrm{mmHg}$, respectively. There were also no significant correlations between blood pressures and UA levels after donation (data not shown).

The UA level was $5.8 \pm 1.3 \mathrm{mg} / \mathrm{dL}$ in male recipients and $5.5 \pm 1.4 \mathrm{mg} / \mathrm{dL}$ in female recipients, and the difference between these levels was not significant $(P=0.51)$. eGFR was correlated with the UA $\left(r^{2}=0.23, P=0.001\right)$, while BMI was not $\left(r^{2}=0.05, P=0.13\right)$ (Fig. 3$)$. The systolic and diastolic blood pressure of recipients after transplantation was $122 \pm 8 \mathrm{mmHg}$ and $75 \pm 8 \mathrm{mmHg}$, respectively, and no significant correlations between blood pressures and UA levels were observed (data not shown).

The numbers of recipients who met the criteria for hyperuricemia are shown in Table 2.

There was a significant difference among males and females in the UA level of the donor before donation, but there were no significant differences in the other parameters. Notably, when the recipients prescribed XO inhibitors were included in the analysis, the proportions of individuals with hyperuricemia were the same for males $(17 / 37,46 \%)$ and females $(11 / 24,46 \%)$.

Next, we performed multiple linear regression analysis on the donor UA levels before and after donation and the UA level of the recipients one year after transplantation (Table 3). As shown in Table 3, the UA levels of donors after donation were significantly correlated with sex, eGFR, and BMI; however, the UA levels of recipients were only correlated with eGFR, suggesting that there was no difference between males and females regarding the UA level in kidney transplant recipients.

There was no significant difference in standardized eGFR values between the donors and the recipients 1 year after transplantation. Donor eGFR was $48.4 \pm 7.6$ $\mathrm{mL} / \mathrm{min} / 1.73 \mathrm{~m}^{2}$, while recipient eGFR was $49.8 \pm 19.3$ $\mathrm{mL} / \mathrm{min} / 1.73 \mathrm{~m}^{2}$. The UA level of the recipients did not differ by donor sex $(P=0.59)$. The mean UA level of recipients whose donors were men was $5.5 \pm 1.5 \mathrm{mg} / \mathrm{dL}$, while that of recipients whose donors were women was $5.8 \pm 1.2 \mathrm{mg} / \mathrm{dL}$. 


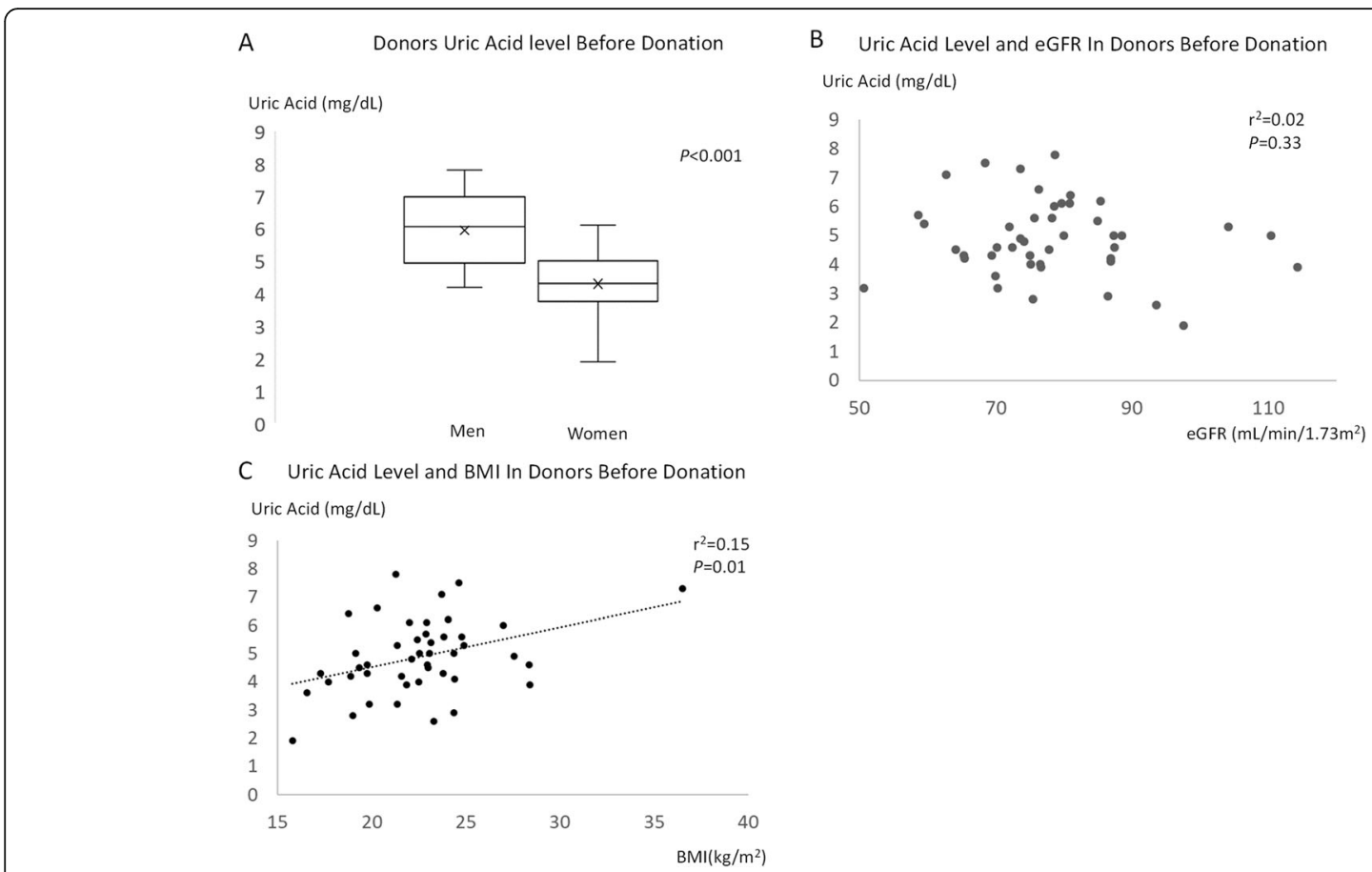

Fig. 1 Correlations between uric acid level and other factors in the donors before donation. a Serum uric acid (UA) levels based on sex. b Correlation between serum UA level and estimated glomerular filtration rate (eGFR). c Correlation between serum UA level and body mass index (BMI)

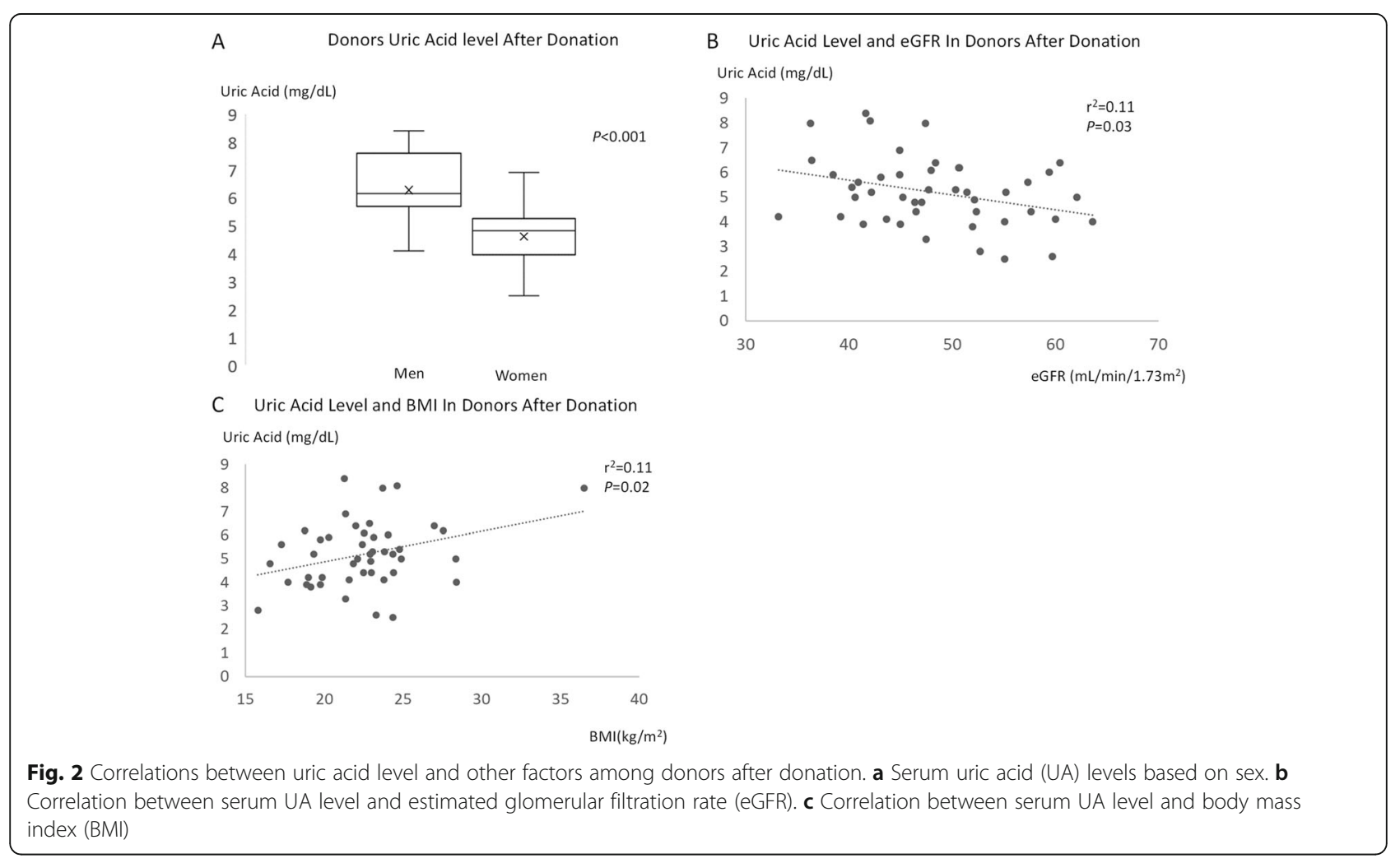


A Recipients Uric Acid level After Transplantation

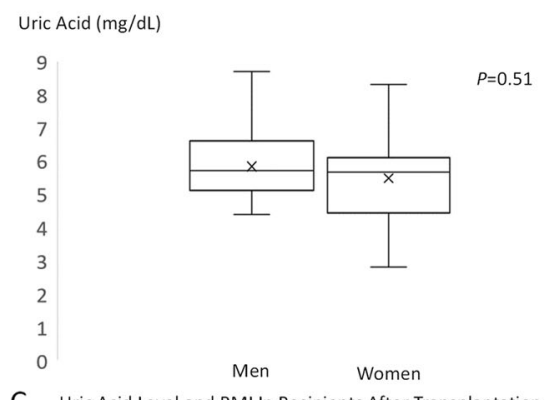

C Uric Acid Level and BMI In Recipients After Transplantation

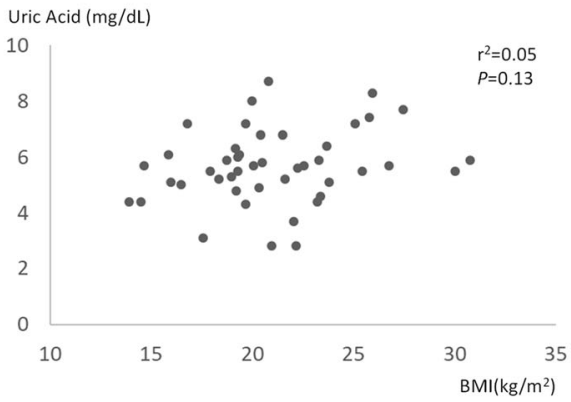

B Uric Acid Level and eGFR In Recipients After Transplantation

Uric Acid (mg/dL)



Fig. 3 Correlations between uric acid (UA) and other factors in recipients 1 year after kidney transplant. a Serum uric acid (UA) levels based on sex. b Correlation between serum UA level and estimated glomerular filtration rate (eGFR). c Correlation between serum UA level and body mass index (BMI)

\section{Discussion}

Although there were no significant differences in standardized eGFR between the donors and the recipients after kidney transplantation in the present study, modulating factors of serum UA levels might be different in both groups. Even though the mean age of donors was higher than that of recipients, male or female sex had a significant effect on the donor UA level before donation. In contrast, there was no significant effect of sex on the recipient UA level.

A previous study of kidney transplantation recipients showed that UA level was associated with male sex, in addition to age and eGFR [12]. In this study, the difference in UA levels among male and female kidney recipients was not significant; this might be a type II error due to the small sample size of this study and the difference in patient characteristics. However, logistic analysis in a previous study showed no sex-related difference in the prevalence of hyperuricemia (defined as male UA $>7.0$ $\mathrm{mg} / \mathrm{dL}$ and female $>6.0 \mathrm{mg} / \mathrm{dL}$ ) among kidney transplant recipients [12]. This result suggests that differences between males and females may have not a very strong effect on UA levels when compared with ordinary CKD patients. In the present study, the prevalence of hyperuricemia in kidney transplant recipients was similar in both male and female recipients.

Iseki et al. [15] showed that the lower threshold of UA $>6.0 \mathrm{mg} / \mathrm{dL}$ was appropriate for women, with regard to an increased risk of end-stage kidney diseases among these patients. A sex-based appropriate threshold for cardiovascular disease or end-stage kidney disease in kidney transplant recipients remains unknown, but a UA level $>6.0 \mathrm{mg} / \mathrm{dL}$ should be avoided in female kidney transplant recipients.

Table 2 The prevalence of hyperuricemia among donors and recipients

\begin{tabular}{|c|c|c|c|c|c|}
\hline & \multicolumn{2}{|c|}{ Men } & \multicolumn{2}{|c|}{ Women } & \multirow[t]{2}{*}{$P$ value } \\
\hline & $\overline{\mathrm{HU}}$ & $\overline{\text { Not HU }}$ & $\overline{\mathrm{HU}}$ & $\overline{\text { Not HU }}$ & \\
\hline Donors before donation & 4 & 12 & 1 & 28 & $0.03^{*}$ \\
\hline Donors after donation & 4 & 12 & 2 & 27 & 0.09 \\
\hline Recipients after Tx & 5 & 20 & 7 & 13 & 0.26 \\
\hline Recipients after $T x$, including those who were prescribed $X O$ inhibitors & 17 & 20 & 11 & 13 & 0.99 \\
\hline
\end{tabular}

$T X$, transplantation; $X O$, xanthine oxidase inhibitors; $H U$, hyperuricemia

${ }^{*} P<0.05$ denotes statistical significance 
Table 3 Multiple linear regression analysis models for serum UA levels in donors and recipients

\begin{tabular}{|c|c|c|c|c|c|}
\hline & & SE & $95 \% \mathrm{Cl}$ & $P$ value & $r^{2}$ \\
\hline \multicolumn{5}{|c|}{ Pre-transplant donors } & 0.44 \\
\hline Sex (female) & -0.51 & 0.168 & $-1.039--0.362$ & $<0.001^{*}$ & \\
\hline eGFR & -0.17 & 0.013 & $-0.043-0.008$ & 0.17 & \\
\hline BMI & 0.27 & 0.046 & $0.006-0.191$ & $0.04^{*}$ & \\
\hline \multicolumn{5}{|c|}{ Post-transplant donors } & 0.52 \\
\hline Sex (female) & -0.53 & 0.163 & $-1.088--0.429$ & $<0.001^{*}$ & \\
\hline eGFR & -0.39 & 0.020 & $-0.113--0.031$ & $0.001^{*}$ & \\
\hline BMI & 0.25 & 0.044 & $0.006-0.186$ & $0.02^{*}$ & \\
\hline \multicolumn{5}{|c|}{ Post-transplant recipients } & 0.26 \\
\hline Sex (if female) & -0.08 & 0.180 & $-0.473-0.253$ & 0.54 & \\
\hline eGFR & -0.45 & 0.009 & $-0.050--0.012$ & $0.002^{*}$ & \\
\hline BMI & 0.15 & 0.047 & $-0.044-0.147$ & 0.28 & \\
\hline
\end{tabular}

$U A$, uric acid; eGFR, estimated glomerular filtration rate; $B M I$, body mass index; $S E$, standard error; $95 \% \mathrm{Cl}$, 95\% confidence interval

${ }^{*} P<0.05$ denotes statistical significance

There are several factors associated with increased serum UA levels [1]. One is the intake of foods that affect UA, such as meat, seafood, and fructose. Another factor is the excretion of UA; the gut and kidney are important in the elimination of UA. In the case of CKD, deteriorated kidney function also has a significant impact on serum UA levels. Moreover, co-administration of drugs may influence UA metabolism and excretion. Because kidney transplant recipients tend to be on polypharmacy, their serum UA level is affected by prescribed drugs $[1,5,16]$. For example, calcineurin inhibitors, such as tacrolimus, induce UA reabsorption and increase serum UA levels. Mammalian targets of rapamycin (mTOR) inhibitors have been used to spare doses of calcineurin inhibitors and may have a positive effect on UA metabolism. In this study, UA levels of recipients who were administered everolimus $(5.4 \pm 1.5 \mathrm{mg} / \mathrm{dL})$ were lower than those of recipients who were not administered this mTOR inhibitor $(5.9 \pm 1.1 \mathrm{mg} / \mathrm{dL})$, but the difference was not significant $(P=0.08)$.

The differences in UA levels among males and females can be explained, in part, by the difference in estrogen levels because estrogen accelerates UA elimination from the kidney [3]. Recently, mycophenolate mofetil (MMF) has been widely prescribed to kidney transplant recipients because it improves prognosis after kidney transplantation [17]. However, MMF has also been shown to decrease serum estrogen levels [18], suggesting that the administration of MMF may play a role in attenuating the differences in UA metabolism among males and females. Since both glucocorticoids and estrogen regulate the production of corticosteroid-binding globulin, another possible explanation is the interaction between corticosteroids and estrogen [19]. To elucidate the sex- related differences in UA levels in kidney transplant patients, more studies focusing on molecular aspects are necessary.

Meta-analysis showed that serum UA level was associated with prognosis after kidney transplant [10]. The precise mechanisms defining how UA levels cause a deterioration in renal function in kidney transplant recipients remains unknown, but several possible mechanisms have been noted. Some of these mechanisms include (1) endothelial dysfunction and vascular smooth muscle proliferation, (2) increased inflammation and oxidative stress, and (3) activation of the renin-angiotensin system $[1,20]$. From this perspective, $\mathrm{XO}$ inhibitors may be considered for kidney transplant recipients to improve renal prognosis. For a long time, allopurinol was the only urate-lowering drug prescribed to patients with renal dysfunction; however, new and safer uratelowering drugs, such as febuxostat, have recently been prescribed to kidney transplant patients [21].

Our study showed that differences in sex had less effects on serum UA levels in kidney transplant patients. In the general population, UA levels will be higher in male patients and urate-lowering drugs will be prescribed to male patients with hyperuricemia. On the other hand, the prescription rate of urate-lowering drugs in female patients is lower in the general population [22], and this may affect the prescription of uratelowering drugs in female kidney recipients. In other words, it may be easier to overlook hyperuricemia in female kidney transplant recipients. In addition, many patients with lupus nephritis tend to be women and these patients are prescribed MMF and corticosteroids for their condition [23]. Patients with these conditions greatly resemble kidney transplant recipients. Therefore, the result of this study seems to be suggestive in considering UA levels in female patients with lupus nephritis.

This study has several limitations. First, the numbers of recipients and donors were small and the sex ratio (male:female) differed between donors and recipients. Although the recipients who were prescribed $\mathrm{XO}$ inhibitors were included as patients with hyperuricemia, we had to exclude them from this investigation because of the significant modification of UA levels by XO inhibitors. Moreover, we used a very simple model and could adjust only three parameters in the multiple linear regression analyses. To elucidate the association between sex and UA levels in kidney transplant recipients, larger studies are necessary. Second, since this is a crosssectional study in a small, single center, the results may not be applicable to other patient groups. Third, as previously mentioned, this study was based on the concept that standardized eGFR was almost the same between donors and recipients. The calculated eGFR was standardized by body surface area [14], and we also adjusted 
body size by using BMI; however, differences in body size between donors and recipients could not be adjusted well. Fourth, we included the cases that experienced rejection, such as antibody-mediated rejection and $\mathrm{T}$ cell-mediated rejection, which may alter renal function. Fifth, we did not exclude patients who were administered losartan, which accelerates the elimination of UA from the kidney. No donors were prescribed losartan, but 2 male and 2 female recipients were prescribed losartan. We believe that the sex-related differences had minimal effects on UA levels, but the UA levels of recipients might be affected by losartan.

\section{Conclusions}

Transplanted kidneys and contralateral donor kidneys have the same function, at least based on standardized eGFR measurements. According to multivariate regression models, the recipient serum UA levels were only affected by eGFR, but the donor serum UA levels were affected by differences in sex, eGFR, and BMI. Recently, UA has been an area of focus because urate-lowering therapy may have a favorable effect on transplanted kidney prognosis. Female recipients experience an increased serum UA level as well as male recipients; therefore, it is critical to pay attention to the UA levels of female recipients in daily clinical practice.

\section{Abbreviations \\ UA: Uric acid; eGFR: Estimated glomerular filtration rate; BMI: Body mass index; CKD: Chronic kidney diseases; XO inhibitors: Xanthine oxidase inhibitors; MMF: Mycophenolate mofetil; mTOR: Mammalian targets of rapamycin}

\section{Acknowledgements}

This study was presented at the 52nd annual meeting of the Japanese Society for Clinical Renal Transplantation in Osaka in 2019.

\section{Authors' contributions \\ MK, YM, YoO, and TN contributed to the research idea and study design. MK, YM, TM, YM, NH, YuO, TU, and YoO contributed to data acquisition. MK, YM, and TN contributed to data analysis/interpretation. MK and YuO contributed to statistical analysis. YoO, HS, HM, and TN contributed supervision or mentorship. All authors contributed important intellectual content during manuscript drafting. All authors read and approved the final manuscript.}

\section{Funding}

This study was partly supported by a Grant-in-Aid for Scientific Research (KAKENHI; grant number 19 K17747).

\section{Availability of data and materials}

The datasets used and/or analyzed during the current study are available from the corresponding author on reasonable request.

\section{Ethics approval and consent to participate}

This study was approved by the Ethics Committee of Nagasaki University Hospital (Nagasaki, Japan) (18041606). Although all patients were informed of the procedures in this study, the Ethics Committee waived the requirement for written consent

\section{Consent for publication}

Not applicable.

\section{Competing interests}

The authors declare that they have no competing interests.

\section{Author details}

'Division of Blood Purification, Nagasaki University Hospital, 1-7-1 Sakamoto, Nagasaki 852-8501, Japan. ${ }^{2}$ Department of Nephrology, Nagasaki University Hospital, Nagasaki, Japan. ${ }^{3}$ Department of Urology, Nagasaki University Graduate School of Biomedical Sciences, Nagasaki, Japan. ${ }^{4}$ Department of Respiratory Medicine, Nagasaki University Graduate School of Biomedical Sciences, Nagasaki, Japan.

Received: 17 July 2019 Accepted: 2 October 2019

Published online: 27 November 2019

\section{References}

1. Feig DI, Kang D-H, Johnson RJ. Uric acid and cardiovascular risk. N Engl J Med. 2008:359:1811-21.

2. Jung JH, Song GG, Lee YH, Kim JH, Hyun MH, Choi SJ. Serum uric acid levels and hormone therapy type: a retrospective cohort study of postmenopausal women. Menopause. 2017:25:77-81.

3. Cao W, Zheng RD, Xu SH, Fan YF, Sun HP, Liu C. Association between sex hormone and blood uric acid in male patients with type 2 diabetes. Int J Endocrinol. 2017;2017:4375253.

4. Vargas-Santos AB, Neogi T. Management of gout and hyperuricemia in CKD. Am J Kidney Dis. 2017;70:422-39.

5. Choi HK, Atkinson K, Karlson EW, Curhan G. Obesity, weight change, hypertension, diuretic use, and risk of gout in men: the health professionals follow-up study. Arch Intern Med. 2005;165:742-8.

6. Kohagura K, Kochi M, Miyagi T, Zamami R, Nagahama K, Yonemoto K, et al. Augmented association between blood pressure and proteinuria in hyperuricemic patients with nonnephrotic chronic kidney disease. Am J Hypertens. 2018;31:480-5.

7. Jalal DI, Chonchol M, Chen W, Targher G. Uric acid as a target of therapy in CKD. Am J Kidney Dis. 2013;61:134-46.

8. Kohagura K, Tana T, Higa A, Yamazato M, Ishida A, Nagahama K, et al. Effects of xanthine oxidase inhibitors on renal function and blood pressure in hypertensive patients with hyperuricemia. Hypertens Res. 2016:39:593-7.

9. Huang Y, Tilea A, Gillespie B, Shahinian V, Banerjee T, Grubbs V, et al. Understanding trends in kidney function 1 year after kidney transplant in the United States. J Am Soc Nephrol. 2017;28:2498-510.

10. Kim ED, Famure O, Li Y, Kim SJ. Uric acid and the risk of graft failure in kidney transplant recipients: a re-assessment. Am J Transplant. 2015;15: 482-8.

11. Kim DG, Choi HY, Kim HY, Lee EJ, Huh KH, Kim MS, et al. Association between post-transplant serum uric acid levels and kidney transplantation outcomes. PLoS One. 2018:13:e0209156.

12. Zhang K, Gao B, Wang Y, Wang G, Wang W, Zhu Y, et al. Serum uric acid and renal transplantation outcomes: at least 3-year post-transplant retrospective multivariate analysis. PLoS One. 2015;10:e0133834.

13. Ishani A, Ibrahim HN, Gilbertson D, Collins AJ. The impact of residual renal function on graft and patient survival rates in recipients of preemptive renal transplants. Am J Kidney Dis. 2003;42:1275-82.

14. Imai E, Horio M, Nitta K, Yamagata K, Iseki K, Hara S, et al. Estimation of glomerular filtration rate by the MDRD study equation modified for Japanese patients with chronic kidney disease. Clin Exp Nephrol. 2007;11: $41-50$.

15. Iseki K, Ikemiya Y, Inoue T, Iseki C, Kinjo K, Takishita S. Significance of hyperuricemia as a risk factor for developing ESRD in a screened cohort. Am J Kidney Dis. 2004:44:642-50.

16. Kumagai T, Ota T, Tamura Y, Chang WX, Shibata S, Uchida S. Time to target uric acid to retard CKD progression. Clin Exp Nephrol. 2016;21:182-92.

17. Halloran PF. Immunosuppressive drugs for kidney transplantation. N Engl J Med. 2004:351:2715-29.

18. US Food and Drug Administration (FDA). Mycophenolate mofetil, US Food and Drug Administration (FDA) approved product information. 2015. https://www.fda.gov/drugs/postmarket-drug-safety-information-patientsand-providers/information-mycophenolate (Content current as of: 07/09/ 2015

19. Feldman D, Mondon CE, Horner JA, Weiser JN. Glucocorticoid and estrogen regulation of corticosteroid-binding globulin production by rat liver. Am J Phys. 1979;237:E493-9. 
20. Kim SJ. Serum uric acid levels and kidney transplant outcomes: cause, consequence, or confounded? Am J Kidney Dis. 2017;70:752-3.

21. Sofue T, Inui M, Hara T, Nishijima Y, Moriwaki K, Hayashida Y, et al. Efficacy and safety of febuxostat in the treatment of hyperuricemia in stable kidney transplant recipients. Drug Des Devel Ther. 2014;8:245-53.

22. Kuo CF, Grainge MJ, Mallen C, Zhang W, Doherty M. Eligibility for and prescription of urate-lowering treatment in patients with incident gout in England. JAMA. 2014;312:2684-6.

23. Tunnicliffe DJ, Palmer SC, Henderson L, Masson P, Craig JC, Tong A, et al. Immunosuppressive treatment for proliferative lupus nephritis. Cochrane Database Syst Rev. 2018;6:CD002922.

\section{Publisher's Note}

Springer Nature remains neutral with regard to jurisdictional claims in published maps and institutional affiliations.

Ready to submit your research? Choose BMC and benefit from:

- fast, convenient online submission

- thorough peer review by experienced researchers in your field

- rapid publication on acceptance

- support for research data, including large and complex data types

- gold Open Access which fosters wider collaboration and increased citations

- maximum visibility for your research: over $100 \mathrm{M}$ website views per year

At BMC, research is always in progress. 